\title{
Design of a Facility for Tsunami Run up Generation to Study Tsunami and Seawall Interaction
}

\author{
Warniyati ${ }^{1}$, Radianta Triatmadja ${ }^{2,}{ }^{*}$, Nur Yuwono $^{2}$, David S. V. L. Bangguna ${ }^{1}$ \\ 'Doctoral Student at Department of Civil and Environmental Engineering, Faculty of Engineering, Universitas Gadjah Mada, Yogyakarta, \\ INDONESIA \\ ${ }^{2}$ Department of Civil and Environmental Engineering, Universitas Gadjah Mada, Yogyakarta, INDONESIA \\ *Corresponding authors: radianta@ugm.ac.id
}

SUBMITTED 26 September 2018 REVISED 15 November 2018 ACCEPTED 11 January 2019

\begin{abstract}
Experimental researches on the tsunami in the laboratory have been conducted using various methods. The use and techniques of tsunami wave generator depend on the objective of the tsunami observation to be conducted. When the objective is the scouring at the downstream of a seawall, the use of a short flume with control discharge seems to be appropriate. A valve with a mechanic controller was equipped to control the discharge from a reservoir into the flume. A numerical simulation of discharge into the flume and the overflow above the seawall was conducted to determine the dimension of the tsunami flume and its generator before construction. The experiments were conducted to simulate the hydrograph of tsunami overflow above the seawall model. The numerical hydrograph is found to be comparable with the experimental hydrograph. This indicates that the tsunami wave generator is capable of simulating tsunami hydrograph and ready for further use of simulations.
\end{abstract}

KEYWORDS Tsunami; wave generator; hydrograph

(c) The Author(s) 2018. This article is distributed under a Creative Commons Attribution-ShareAlike 4.0 International license.

\section{INTRODUCTION}

In recent years, two tsunami events that got significant attention of world researchers are the 2004 Indian Ocean tsunami and the 2011 Japanese tsunami. A number of researches related to tsunami generation in the offshore, tsunami propagation nearshore and its interaction with the coastal defend, land inundation and its mitigation have been published. (Pedersen et al., 2005;Løvholt et al., 2012;Arikawa et al., 2012; Mori et al., 2011; Ghobarah, et al., 2006; Suppasri et al., 2013;Supasinghe et al., 2012).

Tsunami propagation and run-up on land can affect civil engineering structures near the coastline and even further away when the area is relatively flat. The 2004 Aceh tsunami has devasted a large number of buildings in the land caused by tsunami run-up (Ghobarah, et al., 2006). A lot of coastal structures were damage such as breakwaters, seawalls, and sea dikes under the 2011 Japan tsunami. The tsunami hit the coastal structures, overflowed, and subsequently destroyed the coastal structures. The tsunami that propagated far landward and devasted its area was due to the destruction of the coastal structure (Chaudhary et al., 2017). Kato et al., 2012; Jayaratne et al., 2016, described the result of a field survey that was carried out following the 2011 tsunami in Japan. Based on the field survey that was carried out in the eastern coastline of Japan, there were $190 \mathrm{~km}$ long of seawalls and sea dikes were overtopped by the tsunami. Iwate, Miyagi, and Fukushima prefectures were the most affected by the tsunami. There were $99 \mathrm{~km}$ long of the seawall that was damaged by the tsunami overflow. Damage from scouring at the landward toe is the dominant pattern at $49.2 \%$ of the total length of seawall damage (Kato et al., 2012).

The research on tsunami event and its interaction with the coastal defense and structures is still an interesting topic to be conducted, especially for the scouring at the downstream of the seawall. It 
is almost impossible to simulate the tsunami in the hole of the area covering tsunami generation, ocean propagation, nearshore transformation, shoreline processes, runup, overflow, inundation and its impact on the buildings. Therefore, a tsunami generation method in a pertinent area depending on the objective of the observation related to the tsunami is needed. Boundaries condition is needed to simplify the research problem.

Many research on tsunami was conducted through a large-scale laboratory experiment on a flume. Port and Airports Research Institute in Japan have a Large Hidro-Geo Flume at $184 \mathrm{~m}$ long, $3.5 \mathrm{~m}$ wide and $12 \mathrm{~m}$ deep (Allsop, et al., 2014). Germany has a large wave flume (Großer Wellenkanal, GWK) at Forschungszentrum Küste (FZK) in Hannover with total length of about 300 $\mathrm{m}, 5 \mathrm{~m}$ wide and $7 \mathrm{~m}$ deep, equipped with a piston type wave maker with $4 \mathrm{~m}$ stroke (Schimmels et al., 2014). A long flume is certainly capable of various simulation tasks, however; a short flume is a convenient option for particular for simulation.

When the focus of research is tsunami impact on a coastline such as scouring at the downstream of the seawall, a short flume is appropriate to be used. The tsunami could be imitated with a control discharge within the flume. The control discharge could be adjusted to yield hydrograph that represents the tsunami hydrograph.

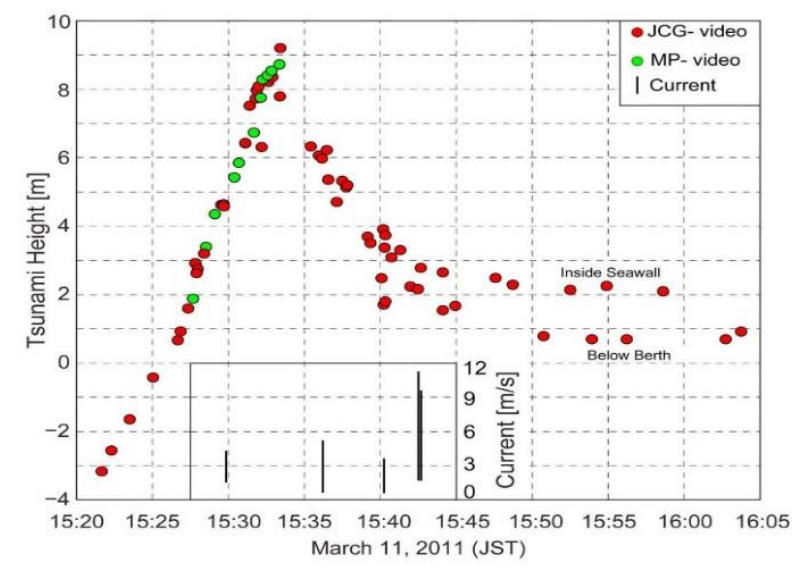

Figure 1. Tsunami height time series derived from the combined MP and JCG videos (Fritz et al., 2012)
The tsunami hydrograph is inspired by the tsunami height time series that derived from the videos of tsunami height in Kesenuma bay during the 2011 tsunami event in Japan (Figure 1). The videos were taken at the Japanese Coast Gard (JCG) and Miyagi Prefecture (MP).

\section{WAVE GENERATION TECHNIC IN LABORATORY}

Several researchs on tsunami and their impact in the nearshore area have been conducted experimentally and numerically. The hypothetical tsunami model in the laboratory may be generated by piston wavemaker, dam break, vertical wave board motion, and releasing a water volume. The methods of tsunami generation in the laboratory depends on the tsunami generative sources (Goseberg, et al., 2013).

\subsection{Piston-type Wavemaker}

Tsunami wave generation in the laboratory is often conducted by piston-type wavemaker. The horizontally moving of the paddle on the water column will release energy to generate a wave. The height and period of the wave that was generated by piston-type wavemaker depend on the paddle stroke. Buldakov (2013) observed the interaction of tsunami wave in the form of plunging or collapsing breaking wave. Chen et al. (2016) conducted tsunami experiment on a wave flume of $40.0 \mathrm{~m}$ long, $0.5 \mathrm{~m}$ wide, and $0.8 \mathrm{~m}$ high where a piston-type wavemaker was installed at one end of the flume. The result of the experiment express that a submerged breakwater could not effectively reduce tsunami scouring, whilst local scouring is the main factor of damage of coastal structures during the tsunami event. The hydraulic experiment of the effectiveness of reinforcement for breakwater stability against tsunami overflow was conducted in a flume with piston type wavemaker (Tsujio et al., 2013). The width and height of the counter mound behind the composite breakwater affected the caisson breakwater stability. 


\subsection{Dam-Break Analogy}

The dam-break analogy is one of generation of longwave and tsunami bore in the laboratory. Chanson, (2006)was developed a simple analytical expression of dam-break analogy for tsunami wave and compare it with experimental data. The dam-break method was employed to generate a tsunami bore to investigate the characteristics of the scour behind the landward slope of coastal dikes through smallscale laboratory experiment(Jayaratne et al., 2016). Kuswandi, et al., (2017) performs a dam break method to generate tsunami bore. Two gates that quickly opening is installed in a flume $20.7 \mathrm{~m}$ long. Between two gate, a volume of water initially stored to generate a tsunami bore when the two gates are quickly opened at the same time. Esteban et al., (2017) conducted an experiment using the dam-break method to study the overflow mechanism above coastal structure due to the tsunami. This method could be applied if tsunami bore is the objective.

\subsection{Vertical Boards Moving}

Generation of tsunami wave which caused by a vertical landslide in the ocean could be modeled by the vertical moving of flume bottom (Raichlen 1970). Upward and downward moving of the flume bottom would generate a tsunami wave to all direction in the flume. This method suitable to be applied in the deep water condition(Goseberg, et al, 2013).

\subsection{Volume Driven}

A volume-driven wave generation has been constructed by storing a volume of water and releasing it under control of a valve-pump system (Rossetto et al., 2011). The tsunami generator could produce a long wave of solitary and Nwaves and also simulate the 2004 Indian Ocean tsunami wave as recorded in the "Mercator" Phuket Thailand.

A water volume was driven tsunami wave generation was conducted (Bangguna, et al., 2016) to imitate the tsunami hydrograph as of 2011 Japan Tsunami event that was derived by Fritz et al., (2012). The tsunami hydrograph has been simulated in the laboratory that generated by a pumping a volume of water into a flume. It was conducted using a flume of $12 \mathrm{~m}$ long, $0.60 \mathrm{~m}$ wide, and $0.45 \mathrm{~m}$ high. The discharge was controlled by a mechanical controller that equipped on the flume to adjust the opening of the valve pump system (Bangguna, et al., 2016).

This paper explains about the design of tsunamigeneration with control discharge on the flume. The tsunami generated by releasing a volume of water from a reservoir into the flume based on a gravitational flow. A numerical and experimental simulation of tsunami hydrograph shown in this paper.

\section{THEORETICAL APPROACH AND RESEARCH METHODS}

\subsection{Flow in Pipes}

In the design of pipelines systems, the flow is calculated using energy equation. According to the energy equation, total energy at two points observed is constant (Equation 1)

$Z_{1}+\frac{p_{1}}{\gamma}+\frac{v_{1}^{2}}{2 g}=Z_{2}+\frac{p_{2}}{\gamma}+\frac{v_{2}^{2}}{2 g}+\sum h_{f}+\sum h_{e}$

Where $Z$ is elevation above a reference, $p$ is pressure, $\gamma$ is spesific weight, $v$ is average pipe velocity, $h_{f}$ is energy loss due to friction, and $h_{e}$ is local a loss.

\subsection{Energy Losses}

Pipeline incur energy loss due to friction and local loss. The local lost may include energy lost at the elbow, valves, inlet devices, outlet to the reservoir. The energy lost due to friction commonly call as primary energy loss and calculated by

$h_{f}=f \frac{L}{D} \frac{v^{2}}{2 g}$

$h_{f}=8 f \frac{L}{D^{2}} \frac{Q^{2}}{\pi^{2} g}$

Where $f$ is friction coeficient, $L$ is pipe length, $D$ is pipe diameter, $Q$ is discharge, $g$ is gravitational acceleration.

The local loss is commonly calculated by 
$h_{e}=k \frac{v^{2}}{2 g}$

$h_{e}=\frac{8 k}{g \pi^{2} D^{4}} Q^{2}$

Where $k$ is local loss coeficient.

Energy lost due to friction is dominant for pipe 30 $m$ or longer (Simon, 1981). In this research, the pipe shorter than $30 \mathrm{~m}$, therefore the primary energy loss was neglected. According to the energy equation, the pipeline system was designed.

\subsection{Hydrograph Tsunami in the model}

The pipeline system was designed to generate a hydrograph tsunami in the flume (Figure 1).

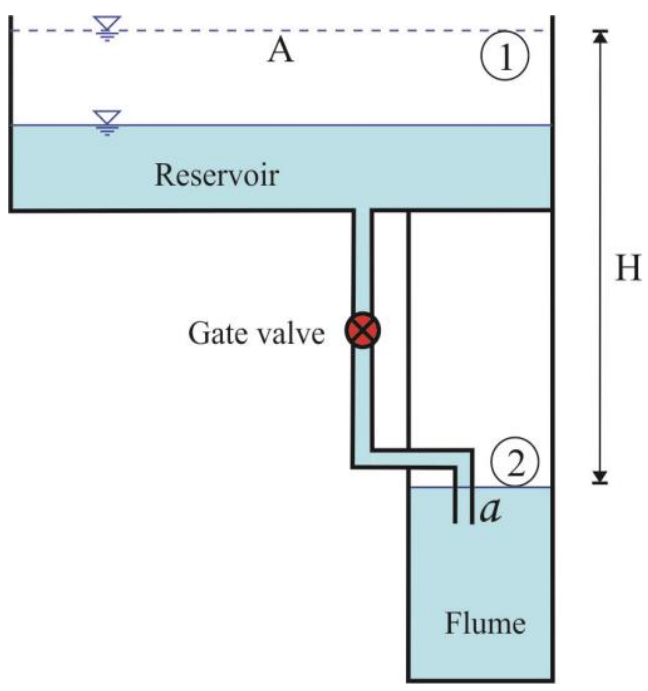

Figure 2. Pipeline system

In the design pipeline system (Figure 2) the pressure in the point 1 and 2 is atmospheric pressure, zero velocity in the point 1 , the differences elevation at both point is $H$, the Equation (1)

$H=\frac{v}{2 g}\left(1+\sum k\right)$

$v_{2}=\left(\frac{2 g H}{\left(1+\sum k\right)}\right)^{1 / 2}$

$Q=C_{d} a\left(\frac{2 g H}{\left(1+\sum k\right)}\right)^{1 / 2}$

Where $v_{2}$ is velocity in the pipe, $a$ is cross-section area of the pipe, $C_{d}$ is discthe harge coefficient.
The water level in the reservoir would be decreased when the valve opened and water flowing from the reservoir to the flume. Differences of water level in the reservoir and the flume at a certain time is

$H^{t}=H^{t-1}-\Delta t \frac{Q^{t-1}}{A}$

Where $A$ is cross-section area of the reservoir, $t$ is time step.

The water level in the flume would increase and be overflowing when the level higher than the seawall model. The overflow may identic with overflow on the weir and calculated by

$Q=\frac{2}{3} C_{d} b \sqrt{2 g} h_{o}^{3 / 2}$

$h_{0}=\left(\frac{3 Q}{2 C_{d} b \sqrt{2 g}}\right)^{2 / 3}$

Where $h_{\mathrm{o}}$ is overflow height.

The tsunami hydrograph could be composed based on the height of tsunami overflow above the seawall model.

The design of control discharge in the flume was numerically simulated based on the theoretical background. Based on the numerical simulation the final dimension on tsunami generation facility was determined as shown in Table 1 . The simulation control discharge from a reservoir into the flume shown in Figure 3.

Table 1. Final dimension of tsunami generation facility

\begin{tabular}{lrl}
\hline $\begin{array}{l}\text { Numerical and physical dimension } \\
\text { data }\end{array}$ & & \\
\hline $\begin{array}{l}\text { Initial water elevation in the reservoir } \\
\left(Z_{1}\right)\end{array}$ & +4.0 & $\mathrm{~m}$ \\
Initial water elevation in theflume $\left(\mathrm{Z}_{2}\right)$ & +0.5 & $\mathrm{~m}$ \\
The cross-sectional area of the & 6.0 & $\mathrm{~m}$ \\
reservoir (A) & 0.25 & $\mathrm{~m}$ \\
Diameter of pipe(d) & 4 & \\
Wide of flume (b) & 0.8 & $\mathrm{~m}$ \\
Length of flume (L) & 9.2 & $\mathrm{~m}$ \\
& 0.09 & $\mathrm{~m}$ \\
The height of seawall model $\left(h_{b}\right)$ & 5 & \\
Discharge coefficient $\left(C_{d}\right)$ & 0.68 & \\
\hline
\end{tabular}


The discharge in figure 3 was developed by control the gate valve at opening time $22 \mathrm{~s}$, delay $3 \mathrm{~s}$, and closing time $24 \mathrm{~s}$. The maximum discharge is about $0.127 \mathrm{~m}^{3} / \mathrm{s}$. Based on the discharge from a reservoir into the flume, the numerical simulation of discharge and overflow height above a seawall model are shown in Figure 4.

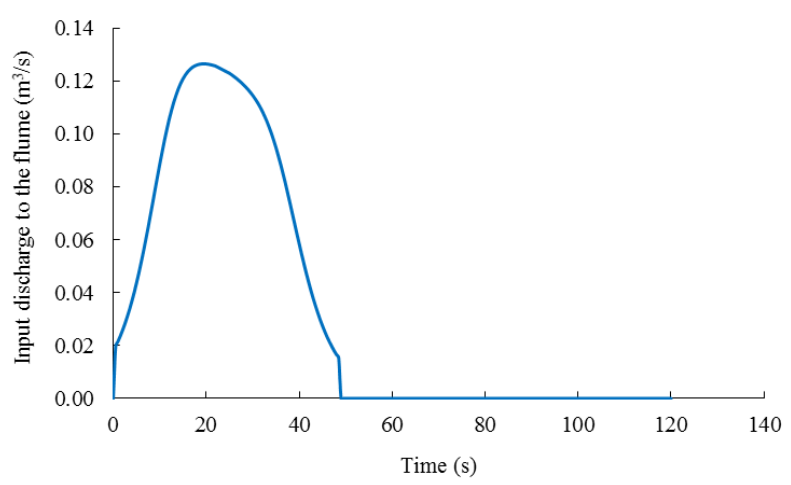

Figure 3. Simulation of discharge from a reservoir into the flume

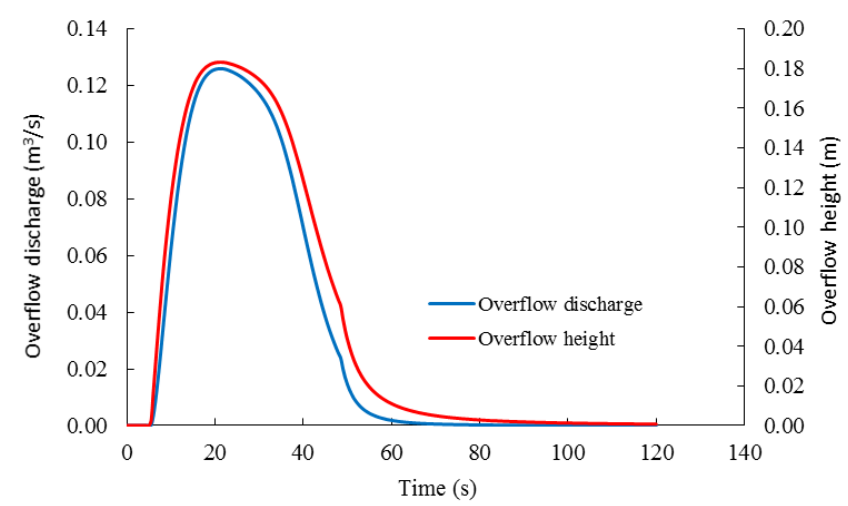

Figure 4. Simulation hydrograph of discharge and overflow height above a seawall model.

\section{RESULTS AND DISCUSSION}

\subsection{A New Tsunami Generation Facility}

A new type of tsunami-generating device has been developed with the control discharge to generate a tsunami. That is a unique and simple device to generate a tsunami within a short flume. The tsunami device was installed in Hydraulics laboratory of Civil and Environmental Engineering Universitas Gadjah Mada. The design of a new tsunami generator based on the gravitational flow. A reservoir at a distance above one end of the flume, a pipeline system installed to connect with the flume. The pipeline equipped with a gate valve with a mechanic controller to regulate water releases from the reservoir. A large volume of water would flush into the flume when the gate valve is open, the water would flowing to the other end of the flume and flowing out to a collecting tank. The collecting tank equipped with a pump to raise the water to the reservoir.

The reservoir, flume and collecting tank were erected in solid construction, consist of brick wall and concrete. A glass panel was installed at the one side of the flume for observation from the outside. The photograph and schematic of tsunami wave facilities are shown in Figure 5 and Figure 6. The size of the reservoir is $3 \mathrm{~m}$ long, $2 \mathrm{~m}$ wide, and $1.5 \mathrm{~m}$ high. The flume is $9.2 \mathrm{~m}$ long, 0.8 $\mathrm{m}$ wide, and $2 \mathrm{~m}$ high. The base differences of reservoir and flume are $2.5 \mathrm{~m}$.

The device was able to model tsunami in the nearshore zone, the process in the shoreline, runup, overflow, and the effect on the structures in the shoreline. In tsunami research, this method could be applied when near-shore surge properties are the main objective. The device does not design to cover the run-down process, therefore the run-down effect should be omitted in the research.

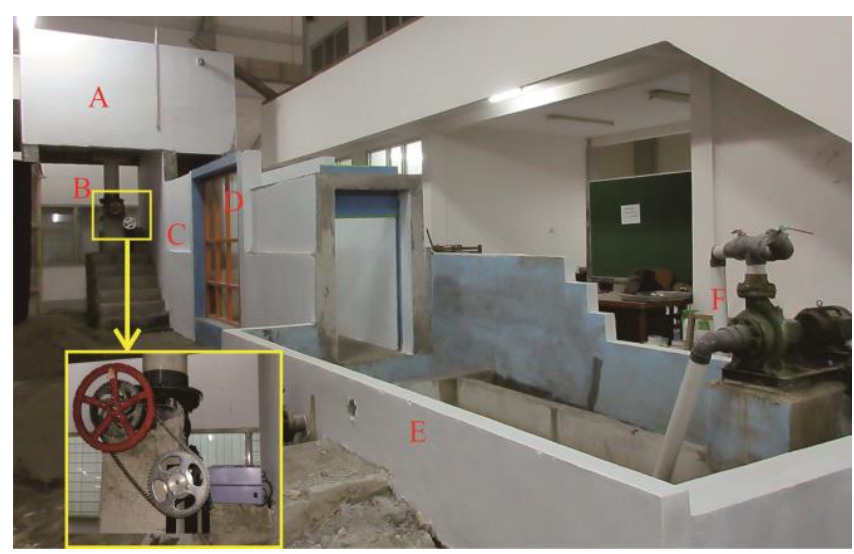

Figure 5. Photograph of tsunami wave facilities. A: reservoir, B: gate valve with mechanic control, C: flume, D: glass panel, E: collecting tank, F: low capacity pump. 


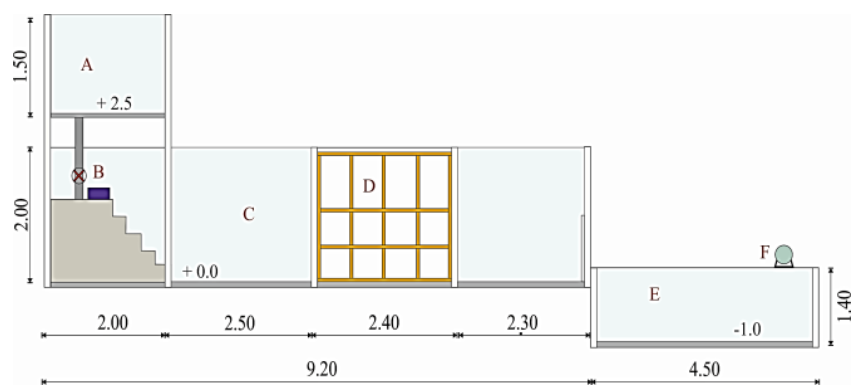

Figure 6. Schematic of tsunami wave facilities. A: reservoir, B: gate valve with mechanic control, C: flume, D: glass panel, E: collecting tank, F: low capacity pump.

\subsection{Tsunami Hydrograph Simulation}

This tsunami generating device was tested to simulate a tsunami hydrograph. The upstream of flume was a fixed bed while a seawall model was installed in the middle of the flume to observe the tsunami event and the overflow above the seawall model. The water height in the flume was observed by a camera recorder. The schematic and photograph of the tsunami overflow test were shown in Figure 7 and Figure 8, while Figure 9 shows the time series of overflow above the seawall model. That is a tsunami hydrograph for some scenarios opening, delay and closing the gate valve.

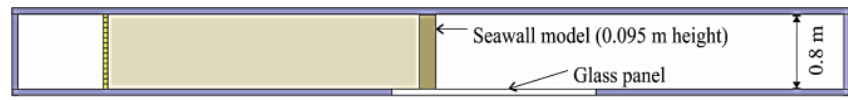

(a) Top view Camera recorder

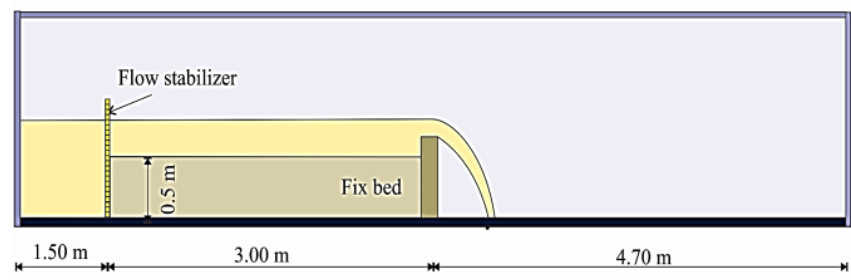

(b) Cross section

Figure 7. Schematic of the overflow test in the flume

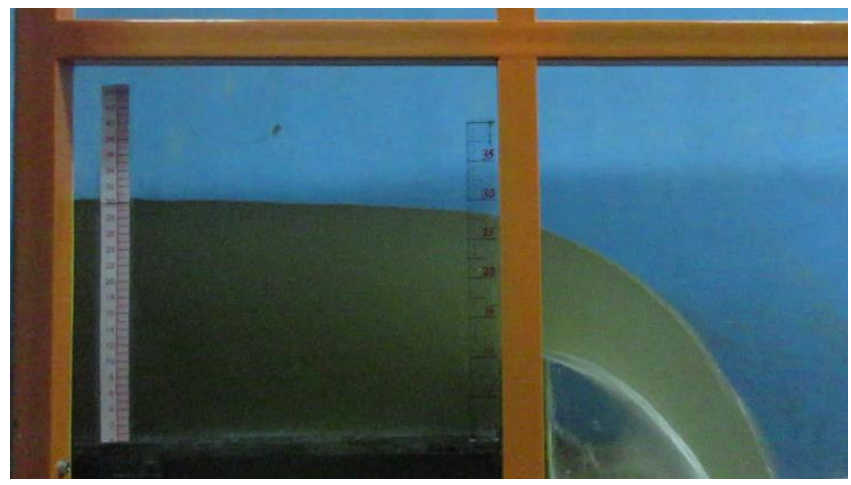

Figure 8. Photograph of tsunami overflow test on the flume

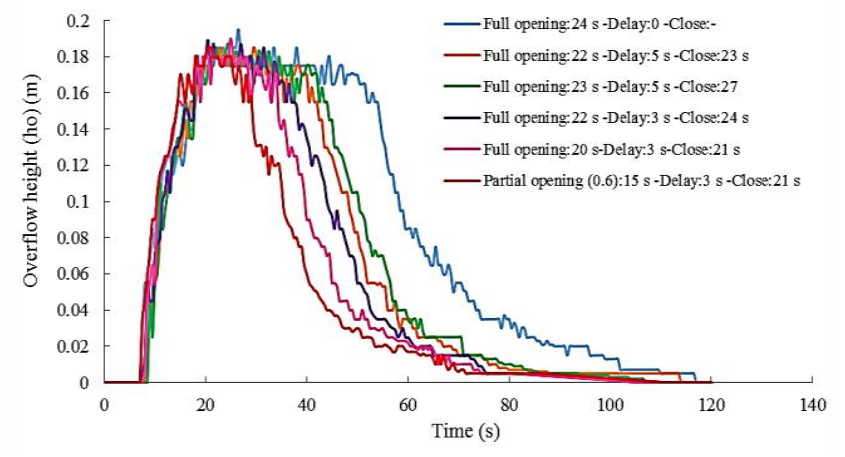

Figure 9. Hydrograph of tsunami overflow

The peak of the hydrograph was almost the same for all of the opening scenarios about $0.19 \mathrm{~m}$. The peak of the hydrograph was narrower when the valve was partially opened. The time for delay and closing influenced the width of the peak and recession of the hydrograph. The peak of hydrograph represents the length of the tsunami. The wider of the peak the longer is the tsunami.

The resulting water height in the flume and the overflow that represent the tsunami hydrograph was strongly dependent on the volume of water in the reservoir, the initial height difference between the surface area in the reservoir and flume, pipe diameter and the opening scenarios of the gate valve.

The comparison of numerical and experimental hydrographs of tsunami overflow is shown in figure 10. The numerical hydrograph is found to be comparable with experimental hydrograph, that indicates that the tsunami wave generator is capable of simulating the tsunami hydrograph.

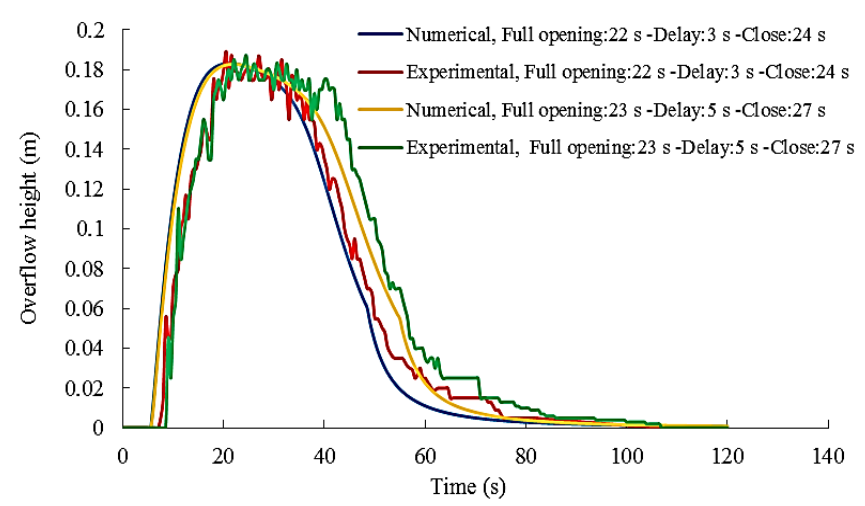

Figure 10. Comparison of numerical and experimental simulation of hydrograph of tsunami overflow. 


\section{CONCLUSION AND RECOMMENDATION}

The tsunami generator with control discharge has been able to simulate hydrograph of tsunami overflow in the laboratory. This short flume may be used for further research, for example, experiments on the interaction of tsunami run up with an obstacle on the beach, scouring and many others.

\section{ACKNOWLEDGMENTS}

The authors express their high appreciation to Lembaga Pengelola Dana Pendidikan (LPDP), Ministry of Finance of The Republic of Indonesia who has provided Beasiswa Unggulan Dosen Indonesia-Dalam Negeri (BUDI-DN) scholarship to the first author and supporting fund on this research. The high appreciation also expresses to the management of the Hydraulic Laboratory Department of Civil and Environmental Engineering Universitas Gadjah Mada who have allowed the authors to build the laboratory facilities.

\section{REFERENCES}

Allsop, W., Chandler, I. \& Zaccaria, M., 2014. Improvements in the physical modeling of tsunamis and their effects. p. 1-22.

Arikawa, T et al., 2012. Failure Mechanism of Kamaishi Breakwaters due to the Great East Japan Earthquake Tsunami. p. 13.

Bangguna, D. S. V. L., Triatmadja, R. \& Yuwono, N., 2016. Simulation of Tsunami Attack on Seawall Caisson. Colombo.

Buldakov, E., 2013. Tsunami generation by paddle motion and its interaction with a beach: Lagrangian modeling and experiment. Coastal Engineering., Volume 80, p. 83-94.

Chanson, H., 2006. Tsunami Surges on Dry Coastal Plains: Application of Dam Break Wave Equations. Coastal Engineering Journal, 48(4), p. 355-370.

Chaudhary, B. et al, 2017. Sliding and overturning stability of breakwater under the combined effect of earthquake and tsunami. Ocean Engineering.
Esteban, M. et al, 2017. Overtopping of Coastal Structures by Tsunami Waves. Geosciences, 7(4), p. 121.

Fritz, H. M. et al., 2012. The 2011 Japan tsunami current velocity measurements from survivor videos at Kesennuma Bay using LiDAR. Geophysical Research Letters, pp. 1-6.

Goseberg, N., Wurpts, A. \& Schlurmann, T., 2017. Laboratory-scale generation of tsunami and long wave. Coastal Engineering, p. 57-74.

Jayaratne, M. P. R. et al., 2016. Failure Mechanisms and Local Scour at Coastal Structures Induced by Tsunami. Coastal Engineering, 58(4), p. 1640017.

Kato, F. et al., 2012. Mechanisms of coastal dike failure induced by the Great East Japan Earthquake Tsunami. pp. 1-9.

Kuswandi \& Triatmadja, R., 2017. Simulation of Scouring Around a Vertical Cylinder Due to Tsunami. Science of Tsunami Hazards, Volume 2, p. 59-69.

Løvholt, F. et al, 2012. Modeling propagation and inundation of the 11 March 2011 Tohoku tsunami. Natural Hazards and Earth System Science, 12(4), p. 1017-1028.

Mori, N. et al., 2011. Survey of 2011 Tohoku earthquake tsunami inundation and run-up. Geophysical Research Letters.

Pedersen, N. H. et al., 2005. Modelling of the Asian Tsunami off the Coast of Northern Sumatra. Engineering, 1755(March).

Rossetto, T. et al., 2011. Physical modelling of tsunami using a new pneumatic wave generator. Coastal Engineering., p. 517-527.

Schimmels, S. et al, 2014. ON THE GENERATION OF TSUNAMI IN A LARGE SCALE WAVE FLUME. Coastal Engineering, pp. 1-10.

Simon, A. L., 1981. Practical Hydraulics. USA: John Wiley \& Sons. 
Supasinghe, P. et al., 2012. Damage and reconstruction after the 2004 Indian Ocean tsunami and the 2011 Great East Japan tsunami. Journal of Natural Disaster Science, 34(1), pp. 1939.

Suppasri, A. et al, 2013. Lessons Learned from the 2011 Great East Japan Tsunami: Performance of Tsunami Countermeasures, Coastal Buildings, and Tsunami Evacuation in Japan. Pure and Applied Geophysics, 170(6-8), p. 993-1018. 